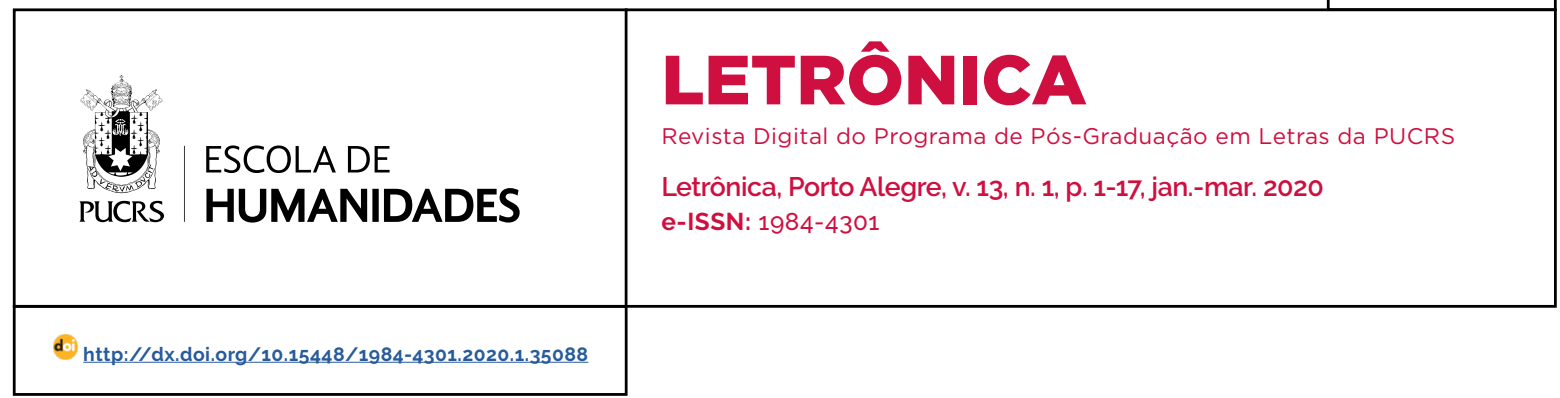

\title{
Una noción poética de la patria mexicana: Esther Tapia de Castellanos y la poesía nacionalista del siglo XIX
}

\author{
Uma noção poética da pátria mexicana: Esther Tapia de Castellanos \\ e a poesia nacionalista do século XIX
A poetic notion of the Mexican homeland: Esther Tapia de Castellanos and the nineteenth-century nationalist poetry

\section{Gabriela Sánchez \\ Medina $^{1}$}

orcid.org/0000-0003-2423-3688 gabrielasanchezmedina@gmail. com

\section{Ariadna Alvarado López ${ }^{1}$ orcid.org/0000-0001-6932-6218 ariadnalvaradolopez@gmail.com}

Recebido em: 28 jul. 2019 Aceito em: 09 dez. 2019. Publicado em: 7 abr. 2020.

\section{(c) (1)}

Artigo está licenciado sob forma de uma licença Creative Commons Atribuição 4.0 Internacional.
Resumin: La obra poética de Esther Tapia de Castellanos es pieza clave para la comprensión de dos fenómenos culturales fundamentales en el proceso de construcción del proyecto nacional de los liberales mexicanos; desde la perspectiva del uso político de la literatura, contribuye a la configuración de un/otro sentido de Patria, pues sus poemas proponen imágenes femeninas que dotan de rostro y sentimiento a la idea de nación que procuraba asentarse por aquellos años; desde la representación puramente literaria, su poesía está llena de retratos del deber ser de la mujer mexicana. En la comunión de ambos aspectos la poesia de Esther Tapia es, al mismo tiempo, un ejercicio de aceptación de los roles tradicionalmente impuestos a la mujer y un acto subversivo en contra de éstos, si consideramos que la incursión de las mujeres en el ámbito de la creación literaria rebasa los límites del espacio cerrado e intimo del hogar y se apropia de los escenarios públicos reservados al varón. En este trabajo proponemos un acercamiento a algunos poemas de Esther Tapia que se publicaron en la prensa del siglo XIX. Tomamos como punto de partida la noción de Patria para analizar, a partir de los mecanismos poéticos empleados, la forma en que se refracta el sujeto femenino en los textos de esta autora.

Palabras clave: prensa. Literatura. Mujer. Patria. Deber ser.

Resumo: O trabalho poético de Esther Tapia de Castellanos é fundamental para entender os fenômenos culturais fundamentais no processo de construção do projeto nacional dos liberais mexicanos; do ponto de vista do uso político da literatura, contribuindo para a configuração de outro sentido do país, seus poemas propõem imagens femininas que dançam e sentem a ideia de uma nação que procurou se sentar durante aqueles anos atrás; a partir da representação puramente literária, sua poesia é repleta de retratos do ser da mulher mexicana. $\mathrm{Na}$ comunhão de ambos os aspectos, a poesia de Esther Tapia é, ao mesmo tempo, um exercício de aceitação dos papéis tradicionalmente impostos às mulheres e um ato subversivo contra eles, se considerarmos que a incursão das mulheres no campo da a criação literária ultrapassa os limites do espaço intimo e fechado do lar e se apropria dos cenários públicos reservados aos homens. Neste artigo, propomos uma abordagem de alguns poemas de Esther Tapia publicados na imprensa do século XIX. Tomamos como ponto de partida a noção de Pátria para analisar, a partir dos mecanismos poéticos utilizados, a maneira pela qual o sujeito feminino é refratado nos textos deste autor.

Palavras-chave: imprensa. Literatura. Mulher. Pátria. Deve ser.

Abstract: The poetic work of Esther Tapia de Castellanos is a key piece for the understanding of two fundamental cultural phenomena in the process of construction of the national project of the Mexican liberals; from the perspective of the political use of literature, it contributes to the configuration of one / another sense of Homeland, because his poems propose feminine images that endow the face of the nation with the idea of a nation that tried to settle down in those years; from the purely literary representation, his poetry is full of portraits of the must be of the Mexican woman. In the communion of both aspects Esther Tapia's poetry 
is, at the same time, an exercise of acceptance of the roles traditionally imposed on women and a subversive act against them, if we consider that the incursion of women in the field of the literary creation goes beyond the limits of the closed and intimate space of the home and appropriates the public scenarios reserved for the male. In this paper we propose an approach to the poems of Esther Tapia that were published in the nineteenth century press. We took as a starting point the notion of Homeland to analyze from the poetic mechanisms employees, the way in which the female subject is refracted in the texts of this author.

Keywords: press. Literature. Women. Homeland. Should be.

\section{Esther: ángel de su hogar}

La aparición de mujeres escritoras en México, como en otros países, no fue repentina ni se encuentra aislada de otros procesos sociales, debe pensarse desde la instrucción recibida por y para las mujeres en las escuelas conventuales, en las casas a través de maestros particulares o de amigas, en las reuniones de costura (con la lectura en voz alta), en tertulias, en las asociaciones literarias y, finalmente, a través de la instrucción pública². La convivencia entre pares fue fundamental en la construcción de la mujerescritora. Este proceso en el que poco a poco las mujeres se fueron sumando y tomaron conciencia de la escritura como ejercicio intelectual puede verse en la prensa del siglo XIX en la que de forma variable resuenan las voces femeninas.

El espacio como escritoras le fue negado a las mujeres en las recopilaciones e historias de la literatura, ya que durante los siglos XVII, XVIII y XIX, parece ser que sólo existía en México la propuesta poética de Sor Juana Inés de la Cruz. El olvido pesó sobre muchas autoras que fueron menospreciadas por la mirada masculina a lo largo de los años, quedando al margen de las antologías en distintas épocas, sólo los nombres de unas pocas, como el de María Enriqueta Camarillo quedó inscrito en algún momento de la historia ${ }^{3}$.
Significativamente, uno de los intelectuales liberales más importantes de la época, José Maria Vigil, realizó una antología poética de escritoras mexicanas para ser presentada en la Exposición Colombina de Chicago, celebrada en 1893. La participación de México en dicho evento dejó en claro que el trabajo doméstico de la mujer fue considerado por encima de su obra intelectual, pues por mandato del presidente Porfirio Díaz se creó en nuestro México una "Junta de Señoras" similar a la de Estados Unidos, autorizada por el Congreso de aquella nación. La junta mexicana fue presidida por Carmen Romero Rubio de Díaz (esposa del presidente) y estuvo conformada por las comisiones de pintura, literatura, bordados, "labores a la aguja", música y cerámica. Los trabajos que se enviaron a la exposición consistieron In:

Pañuelos de Toluca [superiores] a los encajes de Chantilly, finisimos tejidos de las indigenas de Tehuantepec; réplicas del traje de los rurales, bordados en oro y plata, pinturas al óleo, acuarelas sobre porcelana, flores artificiales y dibujos de pelo, etcétera. (DÍAZ y PRADO, 1977, p. 31)

El periodista cubano Gonzalo de Quezada, después de celebrar los admirables bordados, los primorosos tejidos, las excelsas acuarelas, prodigios todos de la inspiración de la mujer mexicana, diria:

La América nuestra está allí, en México; la mujer mexicana nos ha salvado [...] las hijas de Josefa Ortiz de Domínguez y de las indias valientes y sufridas, han colocado a México y a nuestra América entre las primeras naciones del mundo... ellas nos han conquistado más que respeto admiración. iMerecen las palmas de la victoria! (DÍAZ y PRADO, 1977, p. 30)

Por su parte, José María Vigil vería este acontecimiento como un hecho innegable de la posición alcanzada por la mujer en México y su proyección mundial:

Por primera vez en la historia de las exposiciones internacionales se concedió a la mujer el

\footnotetext{
2 La idea de instrucción pública se inició después de la Independencia mexicana y se plasmó en la Ley de Instrucción Pública en 1868 (aunque la Iglesia Católica no la aceptó). En la Ley de Educación de 1870 se señala la obligatoriedad de la educación, pero queda abierta la posibilidad de que los niños reciban la primaria en la familia. Fue hasta 1889 cuando se estableció la instrucción primaria superior con la ayuda de las ideas positivistas. En 1891 se promulgó la Ley Reglamentaria de Educación en la que se estableció como obligatoria, laica y gratuita la educación. Es decir, la escuela pública no existía en el imaginario colectivo de la población, sólo se tenía idea de los colegios religiosos, por tal motivo su aparición e incorporación a la dinámica del pais requirió de un proceso complejo, ya que no se veía a la instrucción pública como una necesidad. Se trata de la construcción de un nuevo espacio social que tuvo implicaciones culturales, económicas, políticas y más (PADILLA, 2002).

3 Sobre este estado de marginación puede verse el texto Escribir como mujeres entre hombres: historia de la poesia femenina mexicana del siglo XIX (GRANILLO, 2010).
} 
derecho, en igualdad con el hombre de intervenir en un evento social de interés colectivo. El haber reconocido su influencia en el proceso de diversificación de las industrias, de las manufacturas y de las artes liberales, significaba poner a un mismo nivel de trascendencia su papel en el hogar y su capacidad de acción pública. (DÍAZ y PRADO, 1977, p. 30)

La participación de México en la Exposición Colombina de Chicago no consistió solamente en una muestra de finas labores domésticas, José María Vigil, a instancia de la "Junta de Señoras" elaboró la primera antología de poetas mexicanas, "cuyo propósito era dar en el exterior más alto y merecido concepto de la cultura literaria alcanzada por la mujer mexicana" (DÍAZ y PRADO, 1977. p. 33). Las opiniones de esta antología se publicaron en El Correo de Chicago, calificándola de "Colección" "curiosa" de poemas escritos por "damas mexicanas" entre las que figuraban, por cierto, Sor Juana Inés de la Cruz, Mercedes Carrasco, María Santoella, Consuelo Fenochio y Esther Tapia de Castellanos. Por su parte, Gonzalo Quezada, que tantos elogios brindó a las manualidades mexicanas, se conformó con decir que se trataba de "versos coleccionados" sin que la antología le mereciera mayor comentario.

Las escritoras antologadas por Vigil, particularmente Esther Tapia de Castellanos, ofrecieron al lector, aunque de manera muy sutil, la imagen de una mujer que podía compartir, sin menoscabo de sus deberes familiares y hogareños, la responsabilidad que suponia su quehacer literario 5 .

Francisco Sosa en la nota biográfica publicada en la antología El Parnaso Mexicano, señala que Esther Tapia de Castellanos nació en Morelia, Michoacán, el 9 de mayo de 1842, se fue a vivir a Guadalajara en 1862 y murió allí en 1897 (1885. p. 5). Otras biografias coinciden en la fecha de fallecimiento ubicando su deceso en la ciudad de Guadalajara, Jalisco. Se sabe que Esther estudió en el Colegio de Santa Rosa María, comenzó a publicar en Morelia y continúo haciéndolo en periódicos jaliscienses cuando su familia se trasladó a vivir a Guadalajara; ahi conoció y contrajo nupcias con Fernando Castellanos de quien tomó su apellido.

Su llegada a Guadalajara coincide con la recién terminada Guerra de Reforma y la amenaza latente de la Segunda intervención francesa; es de suponer que el sentimiento patriótico de la época estaba presente tanto en las tertulias literarias como en el ánimo liberal que Esther Tapia compartía, por lo que paulatinamente se fue integrando a los grupos literarios de la ciudad y su talento poético se comprometió seriamente con la necesidad histórica del momento: darle a la patria un rostro y un alma nacional; así, sus apariciones públicas estuvieron dotadas de dos pasiones: su amor por México y su pasión por las letras; pasiones que logró conjuntar en un par de poemas, ambos titulados "Composición", en los que exaltaba el papel de la mujer mexicana en la construcción y defensa de la patria y que fueron leidos, uno, en el Teatro Nacional de México en una función a beneficio de los hospitales de sangre del Ejército Mexicano, y otro con motivo de un concierto organizado por "las señoritas jaliscienses". En ambos poemas llamados "Composición" es notoria la relación que la poeta establece entre los reclamos nacionales más urgentes y el papel que la mujer desempeñaba en ellos pues en el comportamiento que la patria exige a sus hijas están presentes las configuraciones que Esther Tapia propone para crear una/otra imagen de la mujer y su deber ser.

La poesia de Esther Tapia de Castellanos antologada y prologada por Juan Valle, José María Vigil, Vicente Riva Palacio y Manuel Puga y Acal $^{6}$, es un claro ejemplo de aceptación de los roles tradicionalmente impuestos a la mujer por la cultura patriarcal mexicana del siglo XIX y, a la vez, un verdadero acto subversivo en contra de éstos, si consideramos que para aquella

\footnotetext{
4 Las negritas nos corresponden.

5 En este contexto, en los periódicos de finales del siglo XIX también aparecen textos de Sor Juana Inés de la Cruz, además de los de otras escritoras que tenían cierto reconocimiento en los círculos literarios nacionales e internacionales, como Laura Méndez de Cuenca, María Enriqueta, la cubana Juana Borrero y, por supuesto, Esther Tapia de Castellanos en quien centramos nuestra mirada.

6 Juan Valle compiló su obra en 1862 con el título Álbum de Esther, José María Vigil escribió el prólogo para la primera edición de Flores Silvestres en 1871; este texto está incluido en la edición de la Obra Completa de Esther Tapia publicada en 1905, en donde Puga y Acal también participan con una nota introductoria. Vicente Riva Palacio, incluye en su Parnaso Mexicano una nota biográfica y comentario sobre la obra de la escritora michoacana, publicada por Francisco Sosa en 1885.
} 
época la incursión de las mujeres en el ámbito de la creación y las publicaciones literarias les procuró la apropiación de los escenarios públicos reservados para los hombres $y$, con ello, un quebranto de los límites del espacio cerrado e intimo del hogar destinado para ellas.

El conocimiento de esta escritora es imprescindible para comprender dos aspectos fundamentales del México decimonónico: el uso politico de la literatura en el proceso de construcción del proyecto nacional de los liberales mexicanos ${ }^{7} y$ el sentido estrictamente artístico, la representación puramente literaria, de la configuración de lo femenino. En ambos casos, el papel de la mujer escritora resulta vital para el conocimiento de la cultura letrada de un pais que luchaba, hasta la muerte, por hacerse de un rostro y un destino.

Sobre todo en la segunda mitad del siglo XIX y con el propósito de fortalecer el proyecto nacional, la mentalidad decimonónica configuró el deber/ser de los mexicanos otorgándole a la mujer un espacio propicio para su actividad fundamental: la educación de los hijos. Así, el papel de la mujer mexicana se redujo a una sola labor merecedora de todos sus esfuerzos, el bien de la patria. Esta situación se trasladó al ámbito literario que resultaba ser un medio propicio para la configuración sociocultural de la mujer ya que con el desarrollo textual de los personajes femeninos se creó no sólo una imagen ideal de la mujer, sino también su aparición como mujer imaginaria, como ángel o demonio, como icono fascinante y seductor habitante de la morada del culto de las imágenes (cf. MICHAUD, 2005, p. 153-180).

La producción literaria de aquellos años, particularmente la escrita por hombres -con un tono moralizante y educativo- contribuyó a afianzar una configuración del sujeto femenino que sometió a la mujer a la autoridad del Yo masculino. Por las extensas descripciones de la novela o en la cadencia metafórica de los versos, transita la imagen idilica de la mujer como un ser etéreo, virginal, sumiso, subordinado al hombre y absolutamente moral y subjetivo. Generalmente, los personajes femeninos son exaltados cuando cumplen cabalmente su papel social de amorosa madre, sumisa esposa y tierna hija, lo que les permite vivir una plácida y larga existencia o morir en olor a santidad. Por el contrario, la transgresión de su deber/ ser es motivo de escarnio y duros castigos. El siglo XIX es sin duda el tiempo/espacio de la literatura nacional porque en la búsqueda de establecer en México las condiciones políticas de una nación libre, la cultura letrada se convirtió en una fuente importante de creación y transmisión de una ideologia que procuraba enraizar entre los mexicanos el objetivo más sentido del naciente proyecto nacional: la construcción de la patria.

En el caso concreto de Esther Tapia, en su obra encontramos entrecruzadas la configuración de la Patria y la de la mujer mexicana, sus poemas proponen imágenes de lo femenino que pincelan tanto el rostro como el sentimiento de la nación a partir de las concepciones patriarcales y los roles prescritos desde el deber-ser sancionado culturalmente. La imagen de "el ángel del hogar" aparece para definir y concretar el espacio y el rol social de la mujer como esposa/madre/hija, habitante de un único espacio posible, el espacio doméstico, y llevarla a vivir en el espacio simbólico de la poesia metaforizada en los binomios mujerflor, mujer-patria. Esto se puede ver en los poemas que conforman el corpus de este trabajo.

Para José María Vigil y el pensamiento liberal de la época, la escritura de las mujeres se encontraba en estrecha relación con dos situaciones preponderantes, su condición de mujer esposa

\footnotetext{
El siglo XIX mexicano se caracterizó por la coexistencia de dos proyectos o ideologias que peleaban constantemente y por todos los medios posibles por el derecho a gobernar y determinar las directrices de la vida y el desarrollo económico y político del país: liberales y conservadores defendieron desde la trinchera de la palabra escrita y desde el campo de batalla su propia visión de lo que debería ser México y su futuro; así, durante una centuria este país vivió los estragos de los enfrentamientos entre ambos bandos y sus propuestas ideológicas que oponían argumentos y posiciones monárquicas contra republicanas o centralistas contra federalistas. El contexto general de esta época da cuenta de un periodo de intensos intentos por consolidar una idea hegemónica de la nación mexicana. El Proyecto liberal, que finalmente se impuso desde la época juarista, pugnaba por la construcción de un Estado nacional laico respaldado por un sistema político republicado, democrático y federalista que lograra el progreso económico y político de México, legitimado por la soberanía popular, y que ponía como centro de interés al individuo y sus derechos y libertades como ciudadano; entre ellos, el derecho a la educación y a la libertad de prensa, por ejemplo.
} 
y madre y los temas que por su naturaleza y condición les eran propios. En el prólogo a "Flores silvestres", José María Vigil señala:

[la] lira de Esther, siempre tierna y elevada, siempre pura y melodiosa, expresa con igual facilidad los dulces delirios del amor, la melancolía del desengaño, las efusiones intimas de la amistad, los nobles arranques del patriotismo, los goces inefables de un alma creyente, la tranquilidad del hogar doméstico, embellecido por los cantos y las virtudes de la esposa y de la madre. (Vigil en TAPIA, 1905, p. VII)

El comentario de Vigil resume la idea generalizada que por esa época tenian los intelectuales mexicanos respecto a la mujer escritora. Para ellos el ejercicio literario de las mujeres era una distracción curiosa, una extensión graciosa de su rol fundamental que no las alejaba de su fiel cumplimiento. Vigil celebra las "formas tan suaves y tan perfumadas" en los poemas de Esther porque las entiende como:

[...] inagotables inspiraciones en su propia alma, en la naturaleza que la rodea, en los principios dulces de una moral dulce y humana. Su vida práctica corresponde enteramente a la idea que se refleja en sus bellas composiciones: buena hija, tierna esposa, excelente madre, amiga dulce y afectuosa, es el más encantador ornato del hogar doméstico. (VIGIL, 1977/1893, p. 27) ${ }^{8}$

Por su parte, para Riva Palacio la poesía de esta "joya valiosísima y honra de las letras mexicanas" merecía tal reconocimiento por su condición de mujer que, pese a escribir, siempre tenía presente que no había nada:

[...] tan sano y dulce como su hogar. Nada tan profundo como el amor al compañero de su vida y a sus hijos [...] aunque muy grande es su predilección por las letras, jamás pulsa su lira de oro si el más ligero dolor hiere a alguno de sus seres queridos [...] no ambiciona aplausos, ni se enorgullece de los que se le prodigan:

\begin{abstract}
su gloria consiste en ser buena, en educar bien a sus hijos [...] su apego al cumplimiento del deber como madre y su modestia como poetisa [...] basta[n] para enaltecerla. (RIVA PALACIO, p. 10-11)9
\end{abstract}

La poesía de Esther, como en general la literatura escrita por mujeres, fue valorada por dos circunstancias que el pensamiento patriarcal privilegiaba enormemente: por tratarse de un curioso repertorio de los encantos y la sensibilidad femenina y porque su ejercicio literario estaba subordinado al cumplimiento de sus roles fundamentales.

\section{Ejemplo a seguir}

Para este artículo realizamos una búsqueda de los poemas escritos por Esther Tapia en la prensa publicada en el estado de Michoacán, México, durante la segunda mitad del siglo XIX y los primeros diez años del $X X$, y encontramos cuatro poemas que aparecen en los periódicos La Bandera Roja ${ }^{10}$ (1860), La Lira Michoacana ${ }^{11}$ (1894) y La Mujer Mexicana ${ }^{12}$ (1901). El primero de ellos es un periódico de corte político, mientras que los dos últimos se autodenominan como literarios. Los poemas localizados se titulan "La Patria", "A mi hijo", "Amor de madre" y "Sobre el sepulcro del desgraciado joven D. Juan D. Cobarruvias, después de haber leido un tomo de sus poesias"13. También consideramos dos editoriales, uno publicado en El Prisma ${ }^{14}$ (1881), periódico "de variedades, órgano de la sociedad 'Manuel Acuña', dedicado al bello sexo", y el otro impreso en La Mujer Mexicana (1901).

Las publicaciones periódicas fueron, en muchas ocasiones, el único espacio en el que las escritoras pudieron ver plasmados sus textos. En este sentido, en su ejemplar del 10 de junio de 1881, El Prisma dice ${ }^{15}$ :

\footnotetext{
Las negritas nos corresponden.

Las negritas nos corresponden.

La Bandera Roja. Periódico de carácter político-oficial. Se editó en la ciudad de Morelia de 1859 a 1863, en la imprenta de Octaviano Ortiz e Ignacio Arango. Periodicidad bisemanal (aparecia martes y viernes).

${ }_{11}$ La Lira Michoacana. Periódico de carácter literario, con prospecto. Dedicado a las señoritas. Editado en Morelia, 1894. Periodicidad quincenal (aparecía los dias $1^{\circ}$ y 15 de mes). Imprenta particular de Mariano de Jesús Torres.

12 La Mujer Mexicana. Periódico de carácter literario. Dedicado al sexo bello. Editado en Morelia, 1901. Periodicidad mensual. Imprenta de Mariano de Jesús Torres.

13 Para la transcripción de los poemas se conservó la ortografía de los textos originales.

14 El Prisma. Periódico de variedades. Órgano de la Sociedad Literaria Manuel Acuña. Dedicado al bello sexo. Editado en Morelia, 1881. Periodicidad quincenal (aparecía los días $1^{\circ}$ y 15 de cada mes). Imprenta del Estado.

15 Para las transcripciones de los periódicos en todo este trabajo se conservó la ortografía que aparece en los textos originales.
} 
Ofrecemos las Columnas del "Prisma" -llenos de los más alagüeños deseos- á la disposición de las señoritas que, empuñando la pluma cual otra Inés de la Cruz, cual otra Gertrudis Gómez de Avellaneda, ó cual otra Esther Tapia, hayan trazado en el papel sus cantos para embelesarnos con sus armonias, para sublimarnos con sus puros y tiernos pensamientos, y para abrirnos nuevos y dorados horizontes con las creaciones de su génio. (VELÁZQUEZ, 1881, p. 3)

En este fragmento se pone como ejemplo a seguir a Esther Tapia, pero como el autor, el editor, el director del periódico son hombres, se confina a las mujeres a una expresión limitada por una idea del mundo que no construyen o proponen ellas. Esto se refuerza con la idea de lectoras a las que estaba destinado el impreso:

Sí, á la muger, á las Evas, à la hermosa parte del genero humano, á nuestra bella mitad, á nuestro poderosísimo iman, á nuestro buscado complemento, á ese polo magnético de la especie humana por el cual somos arrebatados, á pesar de nuestras fuerzas y á pesar de nuestro orgullo. Si, dijimos, dedicaremos nuestro Prisma á la muger, á esa hechicera, á esa encantadora Armida, en cuyos brazos se aduerme el valiente, el templado Reinaldo, seducido por sus irresistibles hechizos. ("El Prisma", 1881, p. 1)

Un poco más adelante este mismo texto introductorio dice que este periódico servirá para instruir a las mujeres lectoras, "cuya educación es aún demasiado viciosa" ("El Prisma", 1881, p. 2); la educación no era un asunto solamente de las escuelas, a las cuales llegan por cierto pocas alumnas, los periódicos literarios tomaron la bandera de formadores, pues como señala este impreso, opinaban que: "la muger de hoy solo siente, preciso es también que piense" ("El Prisma", 1881, p. 2). El texto de El Prisma que aquí se cita, señala más adelante que se espera que las mujeres escriban para este medio textos suaves, dulces y coloridos.

En la "Introducción" a La Mujer Mexicana, se incluye una lista de mujeres que, desde el punto de vista de su autor, han destacado a lo largo de la historia. Al llegar al caso de México encontramos lo siguiente:

México tiene también, entre sus heroinas, á Josefa Ortiz de Domínguez, Leona Vicario y Antonia Nava; entre sus poetisas, á Sor Juana Inés de la Cruz, Dolores Guerrero, Ester Tapia, Refugio Barragán de Toscano, Josefina Pérez de García Torres y Gertrudis Tenorio Zavala; entre sus escritoras, á María Aguilar y Sor
Encarnación de Cárdenas; entre sus artistas, a Maria de J. Cepeda y Cosio y Angela Peralta; entre sus fundadoras, á Maria Ana Gómez de la Cortina y Emeteria N. de González; y entre sus damas distinguidas por su posición social. á Maria Ana de Huarte de Iturbide y Cármen Romero Rubio de Díaz. (TORRES, 1901, p. 4)

En este listado se incluye a Esther Tapia. En el mismo texto se dice que "muy justo es que ahora nos ocupemos de rendir nuestras entusiastas ovaciones á <<La Mujer Mexicana,>> que tiene tantos títulos para ser exhibida con gloria ante el mundo civilizado" (TORRES, 1901, p. 4).

En los periódicos michoacanos aparecen textos en los que se plasma un ideal construido desde la mirada masculina, tomamos como ejemplo "La misión de la mujer", publicado en La Mujer Mexicana en 1901:

[...] es, sin embargo, un absurdo indiscutible pretender colocar en sus delicadas manos el timón del navegante, que cruza infatigable las inmensidades del océano, ni el telescopio de astrónomo que sondea los inmensurables espacios del infinito, ni el escalpelo analizador del médico que sorprende el secreto de la muerte en los misteriosos caminos de la vida; ni la triunfadora espada del guerrero que marcha impávido y con semblante sereno por los sangrientos campos de la desolación y la guerra.

No; la mujer no ha sido, no ha podido ser formada para nada de eso; su misión y su destino aparecen por fortuna claros y esplendentes á la luz del Cristianismo, que haciéndola de hecho reconquistar sus perdidos derechos, la colocó en el pedestal inamovible de su fin verdadero, y su importancia social. El templo y su hogar: la piedad y la familia; he aqui el campo aparentemente reducido, pero en relidad [sic] vasto y fecundo en las aplicaciones prácticas de nuestro modo de ser. (TORRES, 1901, p. 35)

Mariano de Jesús Torres apuntaba en La Lira Michoacana sobre la situación de las escritoras:

Es de presumirse que, tanto en tiempo de la dominación española, como durante los gobiernos nacionales desde 1821 hasta 1849, debe haber habido varias señoras que, aun cuando de manera privada, hayan cultivado la poesia en Michoacán; pero el hecho es que bien por timidez y modestia que caracteriza al bello sexo, como por la falta de estímulo y protección que ha tenido, desgraciadamente, la literatura entre nosotros; no se dieron á conocer de una manera pública las damas que hayan escrito composiciones en verso; ni estas llegaron á insertarse en los periódicos oficiales ó en los independientes que se publicaron en diversas épocas. (1894, p. 613) 
Los periódicos, semanarios, folletines, hojas sueltas, etcétera, sirvieron para difundir tanto noticias como ideas o caricaturas de carácter político, asi como las novedades literarias que muchas veces tenían la función de acercar al público lector al ideario liberal para el desarrollo social. La educación y la moral dieron sentido a las publicaciones cotidianas de un país que quería proyectarse al mundo como moderno y civilizado (PÉREZ-RAYÓN, 2014, p. 2-3). En las páginas de la prensa las mujeres, mediante la literatura, encontraron la posibilidad de expresar su visión de mundo, así, encontramos los textos de diversas autoras que hasta ahora son poco conocidas, junto con los versos de Sor Juana Inés de la Cruz y los de otras poetas que tenian cierto reconocimiento en los círculos literarios nacionales e internacionales, como Laura Méndez de Cuenca, María Enriqueta, la cubana Juana Borrero y, por supuesto, Esther Tapia de Castellanos en quien centramos nuestra mirada.

\section{La Patria en palabras de Esther}

Proponemos realizar un análisis poético de los poemas que encontramos publicados en la prensa michoacana (ver cuadro 1) ${ }^{16}$, a partir de la forma en que Esther Tapia se sitúa como sujeto femenino en poemas de su autoria; se trata de considerar cómo esta autora se permite la posibilidad de tomar la palabra en un mundo literario dominado por los hombres, lo que implica haberlo hecho prácticamente sin modelos o reinterpretando la estética de su tiempo, se trata de un diálogo con la tradición en un plano individual, cultural y literario. Para Taylor (1996) la identidad está primordialmente determinada por el lenguaje que empleamos para referirnos a nosotros mismos, para construir nuestro autoconcepto; las expresiones lingüísticas que empleo para describirme a mi mismo son constituyentes y constitutivas de mi ser; a través del lenguaje conformo lo que soy.

Cuadro 1 -Título de los poemas

\section{Título de los poemas}

Periódico

Número, tomo, fecha, página
"Sobre el sepulcro del desgraciado jóven
D. Juan D. Cobarruvias, despues de ha- ber leido un tomo de sus poesías"
La Bandera Roja
"La Patria"
"A mi hijo"
"Amor de madre"
Noviembre 23 de 1860. Número 159 Tomo I, p. 4
La Lira Michoacana
La Mujer Mexicana
1894, pp. $640-641$
1901, pp. 65-66
1901, pp. 92-93

Fuente: Elaboración propia con base en el archivo de la Hemeroteca Pública Universitaria Mariano de Jesús Torres de la Universidad Michoacana de San Nicolás de Hidalgo, México.

En este trabajo el acento se pone en la idea Patria que fue conformando un nuevo imaginario en un pais que intentaba construirse. Hablamos de una subjetividad que esta escritora proporciona al incorporar la objetivación de sus procesos mentales y creativos, en lucha con el orden establecido que no deja mucho espacio a la expresión de un yo propio, por esta razón el yo de las mujeres es una aportación decisiva a la tradición literaria de nuestro país. De acuerdo con
Lucrecia Infante Vargas, tradición literaria "refiere un corpus cuyas temáticas y estrategias narrativas se retoman o reproducen de manera similar de un autor(a) a otro(a), e incluso de una generación a otras subsiguientes, hasta constituirse en una especie de herencia cultural que, a su vez, se instituye como un antecedente histórico-artístico que establece los parámetros de validez y calidad de las obras subsecuentemente producidas dentro del mismo terreno creativo" (2008, p. 72).

16 Hemos decidido incluir las referencias hemerográficas en el Cuadro 1, no se reportan a lo largo del análisis de los poemas para dar fluidez a los argumentos que se presentan en esta parte del trabajo. 


\section{Sobre el sepulcro del desgraciado joven D. Juan D. Cobarruvias, \\ Después de haber leido un tomo de sus poesias}

¿Por qué tan tarde tu divino acento Ha resonado en mi infeliz oído? ¿Por qué tu triste y lúgubre gemido Cuando en el mundo estabas no escuché? ¿Por qué no oí ese acento que revela La mas honda tristeza y la amargura, Por qué el sello de horrible desventura En tu frente grabado no miré?

Yo habría volado á delirar contigo Yo habria enjugado tu ardoroso llanto, $Y$ al ménos en tu horrible desencanto Te hubiera sonreido la amistad. Cuando llorabas con filial cariño De tu madre la muerte desgraciada, Yo contigo en su tumba infortunada Hubiera lamentado tu horfandad.

La maternidad y, con ella, todos los aspectos y asuntos relativos al ejercicio de ella, aparecen en la obra de Esther Tapia como un continuo reconocimiento a la figura de la madre como centro y motor, tanto de la formación de los hijos como de su bienestar emocional y espiritual. La muerte de la madre supone un doloroso vacio que sólo el afecto de otra mujer versada en los asuntos maternales puede ayudar a paliar. Así, en estos versos, escritos además tras la muerte del joven poeta, Esther Tapia no sólo configura el dolor por la muerte temprana de aquel a quien están dedicados, también expone uno de los ejes fundamentales de ser madre: la empatía ante el sufrimiento y su consecuente y solidaria necesidad de aliviarlo, tal como lo señala en los versos subsecuentes:

Cuando llorabas de este mundo necio

La falsedad, el dolo, los engaños

Tus pesares y tristes desengaños

Yo habria sabido con dolor llorar.

iPero ay!... escrito estaba que del mundo

Solo, triste, pasaras el camino,
$Y$ era tu horrible y tétrico destino

En tu temprana edad la muerte hallar.

Es común encontrar que por los versos de Tapia de Castellanos transite una imagen pesimista del mundo al que no vacila en describir como necio, falso o doloso. Esta idea casi siempre se encuentra vinculada a la faceta de madre que procura preparar y defender a sus hijos contra los males mundanos, aparece también en los poemas de corte didáctico-amoroso en los que previene a las niñas inocentes de los malos haceres del hombre-colibrí. En este poema tal pesimismo se da en relación con la orfandad y lo que ésta supone como falta de alivio y consuelo maternales, pero, aún más, también asociado a la propia muerte del homenajeado, de ahí que la poeta se duela por no haber podido ser una madre para él.

Cual águila pasaste por el mundo Dejando solo una brillante huella, Fuiste una antorcha luminosa y bella Que el viento en sus furores apagó, "Fuiste un brazo del árbol de la ciencia" Que á la doliente humanidad salvaba, iCuando á su sombra el alivio hallaba Horrible tempestad lo destrozó!

Pobre, sencilla, cándida violeta Que el valle de la vida perfumaba, Cuando á la aurora bella se mostraba, El huracán furioso la arrancó. iPobre boton que deshojara el viento! iPobre flor agostada en su mañana! iCiencia, saber, ni juventud lozana La muerte en su furor no respetó!

Resulta curioso que Esther Tapia recurra a la unión de dos conjuntos de elementos que en la poesía de la época ayudaban a determinar el carácter y posición de los géneros; por una parte, el águila, la antorcha luminosa y el brazo del árbol de la ciencia como elementos metafóricos para el sexo masculino, su inteligencia y fortaleza naturales; mientras que la violeta, pobre, sencilla y cándida, el botón desojado y la flor agostada, 
como metaforizaciones de la delicadeza y fragilidad femenina; no obstante, en este poema se conjuntan para configurar la imagen de la juventud y la inocencia destruidas por la muerte. Las imágenes de la violeta que perfumaba el valle de la vida y que el huracán y sus vientos arranca y deshoja, aparecen constantemente en la poesía de esta escritora vinculadas a la idea didáctica en los poemas de corte amoroso, por lo que es interesante que recurra a ellas para configurar la imagen doblemente dolorosa de la muerte juvenil como se advierte en los siguientes versos:

Ave que en los cipreses elevados

Te arrullaba la brisa suavemente

Al cantar tus pesares tristemente

"Desapiadado el cazador te hirió."

Tierna ave... flor... antorcha... ya no existes

iÁrbol, tan solo recordamos ahora,

Que á tu sombra feliz y bienhechora

Aquel que padecia su alivio halló!

Ave.... nos quedan tus divinos cantos,

Con ellos una herencia nos dejaste,

Antorcha.... ya no existes, te apagaste

Solo el destello de tu luz se vió.

Flor, no existes tampoco, te abrasaron

Del sol los rayos del ardiente Mayo,

Ya doblegaste tu flecsible tayo,

"Solo el aroma de la flor quedó."

El destello de luz dejado por la antorcha, y el aroma que subsiste a la desaparición de la flor, que aparecen plasmados en las dos estrofas anteriores, se pueden leer como elementos tanto de consuelo por una vida que, aunque breve, fue vivida, así como de la herencia poética que deja tras su muerte el artista, recordemos que el poema está dedicado a un joven poeta y, por ello, a pesar de su fallecimiento, queda el consuelo de sus versos:

Envidiosa la muerte contemplando

Por tu mano la victima salvada

Con su mano fatal y descarnada

Sobre tu frente la guadaña hundió.

Y envidiosa tambien de los laureles

Que preparaba para ti la gloria,
Quiso estinguir tu nombre y tu memoria

iPero la fama sus deseos burló!

iNo morirá su nombre, ella le dijo, Mientras aliente un pecho mejicano, Yo con su sangre y con mi propia mano En su patria infeliz lo grabaré.

Y aun mas allá de los inmensos mares En mis álas y en brazos de la gloria, Su nombre, su martirio y su memoria A la faz de ambos mundos mostraré!

Y no murió tu nombre tan querido, Lo adora tu familia desgraciada, Lo venera tu pátria infortunada Y está grabado en cada corazon. Las virgenes hermosas de tu suelo Cipreses plantarán junto á tu fosa, Con blancas flores regarán tu losa, La bañarán con llanto de afliccion!

Tus amigos con palmas y laureles Adornarán tu losa funeraria,

Y de sus lábios mística plegaria Hasta el cielo do moras llegará. A la hora del crepúsculo sombrio Un ángel bello cantará tu gloria, Su eco será la postrimer historia Y en sus hojas tu nombre quedará.

Vive alegre en el cielo, que en el mundo No olvidamos tu nombre tan querido, Por tu martirio lúgubre gemido iNo dejará de resonar jamas! Ni un solo mejicano habrá que olvide Tu lamelitable y desgraciada historia, iEs inmortal de un mártir la memoria! No morirá tu nombre: iduerme en paz!

Esther Tapia.

Morelia, Octubre 17 de 1860.

En lo que se refiere a la configuración de la patria, Tapia de Castellanos hace evidente en el poema "La Patria" el indisoluble vínculo entre la mujer/ madre y la patria como madre; es decir, manifiesta 
la importancia moral y social de la crianza y el amor a los hijos, no sólo por lo que importa hacia el interior del hogar sino porque, por extensión, se beneficia con ello a la sociedad, sobre todo, cuando se trata de crear una noción de lo nacional ${ }^{17}$ :

<<iPatria, patria, nombre santo;

nombre el más dulce y querido;

voz de celestial encanto;

que hace derramar mi llanto

con su mágico sonido!〉>

Asi una mujer decia,

y reclinado en su seno

un tierno niño la oía,

diciéndola de ansia lleno:

¿Qué es la Patria, madre mía?

Hijo ese nombre adorado

es manantial de emociones;

es lo que hay más venerado,

es un conjunto sagrado

de recuerdos é ilusiones.

De las treinta y cuatro estrofas que integran el poema, se destacan aquellas en las que hay una amorosa descripción de la geografía que, indudablemente se entiende como una extensión del amor a la madre:

Amo sus grutas hermosas

por los amores formados,

sus magníficas cascadas,

y sus fuentes primorosas

y sus brisas perfumadas.

Amo sus altivos montes

do alza el ave sus cantares;

amo sus potentes mares,

sus lejanos horizontes

y sus bosques seculares.

Y del paisaje siempre asociado a los lugares más entrañables de la existencia:

\begin{abstract}
Son los templos majestuosos
donde de niños rezamos;

el huerto donde jugamos,

y los árboles frondosos

á cuyo pié nos sentamos.

El llano donde corrimos

tantas ligeras mariposas;

la fuente donde bebimos,

y el arroyuelo que vimos

serpentëando entre rosas.
\end{abstract}

Todos estos elementos con los que la madre procura explicarle al hijo su noción de patria, son determinantes para delinear su grandiosidad e importancia, así como señalar la urgente necesidad de inculcarle a los hijos la veneración y el respeto que la patria merece en tanto hogar, madre y lugar de pertenencia:
Es el sitio do nacimos,
donde primero lloramos
y la luz primera vimos;
de el amor filial sentimos
y el de una madre gozamos.
Es aquel hogar risueño
donde vivió nuestro padre,
donde veló nuestro sueño
con un semblante halagüeño
nuestra cariñosa madre.

Los versos de las últimas quintetas son los que mejor explicitan la labor fundacional de la mujer como fomentadora de valores civicos a través de los cuales procura sembrar en sus hijos el significado y compromiso del amor patriótico:
No ver más contiendas quiero
De hermano contra el hermano;
Mas si un osado extranjero
La ultraja, ver en su mano
Siempre empuñado el acero.

\footnotetext{
17 Liah Greenfeld se refiere al nacionalismo como el "conjunto de ideas y de sentimientos que conforman el marco conceptual de la identidad nacional", en donde la identidad nacional es considerada como la identidad fundamental y definitoria para la construcción del individuo en el mundo moderno, frente a otras muchas identidades que le son próximas (1999, p. 18).
} 
En fin, quiero, hijo del alma,

Para ella el sol de la gloria,

De la paz la dulce calma,

De las virtudes la palma

Y el laurel de la victoria

A continuación tenemos el poema "A mi hijo":

\section{A mi hijo}

¿Qué serás tú, mi bien sobre la tierra,

Hombre de paz ó génio de la guerra?

¿Lámpara viva del Sagrado altar?

$¿ O$ las bellezas que natura encierra

En inspirado acento cantarás?

Gabino Ortiz

Es una noche preciosa,

de esas noches sosegadas,

de la luna iluminadas

por la ténue claridad:

Hasta mi estancia penetran

sus rayos tan hechiceros:

imisteriosos compañeros

De mi grata soledad!

Arrullo tierna en mis brazos

al hijo de mis amores;

hermosa flor de mis flores,

perla de mi corazón.

El reflejo de la luna

baña su apacible frente;

limpio lago trasparente

que hace nacer mi ilusión.

Beso sus lindas mejillas,

una y mil veces amante;

y en mi seno palpitante

le estrecho con santo amor:

$Y$ otras mil veces y ciento

beso sus ojos divinos,

y sus labios purpurinos

cual las hojas de la flor.

En su alas atrevidas

mi imaginación ardiente

me arrebata velozmente

y pienso en su porvenir.
Y dos lágrimas resbalan

mis mejillas abrasando,

y murmuran suspirando:

"¿qué será, mi ángel, de ti?"

¿Qué serás sobre este mundo

hijo del alma inocente

fruto de mi amor ardiente,

idolo del corazón?

¿Por qué adivinar no pudo,

mi bello ángel, tu destino?

¿hallarás en tu camino

las espinas de la flor?

Las preguntas de la poeta posibilitan la inclusión poética de los elementos con los que, aprovechando el rol de la madre que vela el sueño de sus hijos, la voz lírica desliza tanto su amor al hijo como su vital preocupación por el futuro y bienestar de su crio y revela la voz de una mujer en la máxima ostentación de una de las caracteristicas del "Ángel del hogar": la salvaguarda de los hijos, tema y preocupación constante en este poema.

¿Me será dado mirarte (si Dios me da larga vida) en tu juventud querida, fuente de toda ilusión?

¿Te miraré enamorado de alguna joven hermosa, entre feliz y celosa porque me roban tu amor?

¿Te miraré entre el incienso al pie del altar sagrado, ante un pueblo arrodillado que ve en tus manos á un Dios?

¿En la cátedra sublime oiré en el templo sonando tu noble acento, enseñando nuestra santa religión?

¿Y entre los cándidos niños sembrando en sus corazones evangélicas lecciones de moral y de virtud: 
Compasivo sacerdote

junto al pobre moribundo

que va á partir de este mundo

y el cielo le muestras tú?

¿Te veré noble guerrero,

en medio á feroz batalla

asaltado una muralla,

de bélica trompa al són;

Y de tu patria querida,

veré en tu mano altanera

tremolando la bandera

por tí cubierta de honor?

El amor a la patria fue para Esther Tapia un compromiso ineludible tanto como la crianza de los hijos, el cuidado de la casa y su ejercicio poético. La educación cívica y espiritual de los vástagos era obligación natural y privilegio de la madre; al pasar de obligación a privilegio el vínculo filial que se forma adquiere un carácter extraordinario: el amor filial se revela fundamental, incorruptible e incondicional y estará alli para ofrecer a los hijos el soporte necesario para su desarrollo adulto. Es destacable en este poema que las preguntas de la madre sirvan para recorrer las opciones formativas del hijo, con lo que se da cuenta del contexto social y cultura de la época y su influencia reciproca en la conformación de sectores sociales y los espacios para su desarrollo, en este caso, los espacios reservados a los hombres: el sacerdocio, el magisterio, el ejército y la posibilidad de complementar, cuando menos los últimos, con la vida conyugal.

¿Te veré artista inspirado,

coronado de laureles,

creando con tus pinceles

virgenes cual Rafael;

O escucharé los sonidos

de tu lira armoniosa

que en la noche silenciosa

le canta al Dios de Israel?

¿Serás acaso un Bellini, una fuente de armonía

que la dulce melodía del cielo nos haga oír?

¿O serás tal vez un sábio,

un astrónomo profundo,

ó un legislador fecundo

que haga á su patria feliz?

¿O serás, como tu abuelo, un agricultor honrado, que virtuoso y respetado vivas dichoso y en paz?

¿Serás, como él, tierno padre de los buenos moradores

y felices labradores que cultivan tu heredad?

¿Y pasarás tu existencia como ha pasado halagüeña nuestra existencia risueña entre trabajo y amor?

Quiera el cielo, hijo del alma, que asi resbale tu vida, y la ambición, acogida no halle en tu corazón.

Sean el campo y el cielo los solos libros que leas, y más sabio nunca seas que el que feliz sabe ser.

Nunca pruebes los placeres de la corte corrompida, que harán en tu alma una herida que apresure tu vejez.

Cien años de nobles goces, no vale, niño inocente, ni una hora solamente de santa tranquilidad.

Bajo dorados palacios mejor se esconden, traidores, los más punzantes dolores; y el oro no da la paz.

Vive, pues, como tus padres, siendo agricultor honrado,

y feliz respetado,

larga vida te dé Dios.

Mas si quieres que tus goces 
no turbe fiera desdicha,

busca en la virtud la dicha,

y en tu propio corazón.

Esther Tapia de Castellanos.

El colofón didáctico del poema refuerza tanto la imagen del amor maternal como la configuración del rol de madre en su faceta más importante e imperiosa: la formación cívica en los valores necesarios para el contento de la sociedad y el mejoramiento de la patria.

Dividido en tres partes, el poema "Amor de Madre" está dedicado a su hijo, es la oportunidad poética de Esther Tapia para cantarle a la Mujer/ Madre que desde su espacio asignado se resuelve conquistadora de su propio lugar, el que sí le pertenece, el que ella busca y gobierna: el espacio del amor maternal como espacio simbólico en el que se unen, para renovarse y dignificarse, los roles fundamentales de su deber/ser.

En la primera parte los versos dibujan, a partir de la mirada amorosa de la madre, más que la belleza o cualidades de su pequeño hijo, las sensaciones y sentimientos que despiertan y acompañan a la maternidad que es vista no como una obligación sino como un privilegio divino:

Un niño tan rubio tengo,

tan agraciado, tan lindo,

que la dicha llena mi alma

cuando en mis brazos le miro.

[...]

Tiene unos ojos tan grandes,

tan dulces, tan expresivos,

que de mi amor son espejo

en que orgullosa me miro.

[...]

No sé si será tan bello

cual le juzga el amor mío

ó si será que los ojos

de madre tierna en él fijo.

No lo sé; más al mirarle

siento un inefable hechizo,

y pienso que más hermosos

no son los ángeles mismos.
[...]

Si le estrecho entre mis brazos

y le beso y le acaricio,

en esos dulces momentos

algo del cielo adivino.

La segunda parte del poema hace evidente que la maternidad, ya vista como un privilegio, es una condición vital que enaltece al espíritu femenino incluso más que el matrimonio. Es decir, que de los roles asignados a la mujer es la maternidad la que la instaura en el espacio simbólico del amor verdadero y, con ello, la convierte en la depositaria de lo único que los hombres no podrán poseer jamás, la oportunidad de crear y criar más allá de la obligación paternal que supone su condición de proveedores materiales:

$$
\begin{aligned}
& \text { ¡Cuán desgraciadas esposas } \\
& \text { las que no tienen un hijo! } \\
& \text { iCuán infelices! no saben } \\
& \text { lo que es el amor de un niño, }
\end{aligned}
$$

Tener un hijo significa acceder a sensaciones, sentimientos y experiencias que, en el poema, aparecen en un horizonte no compartido con los hombres; la maternidad y el amor que esta genera posicionan a la mujer en un lugar mucho más amplio y abarcador que el representado por el hogar físico; es decir, más allá de lo que son las tareas obligadas de una madre, esta condición le otorga a la mujer un poder simbólico que de otro modo no puede ser concebido, por lo que carecer de ello es doloroso y lamentable:

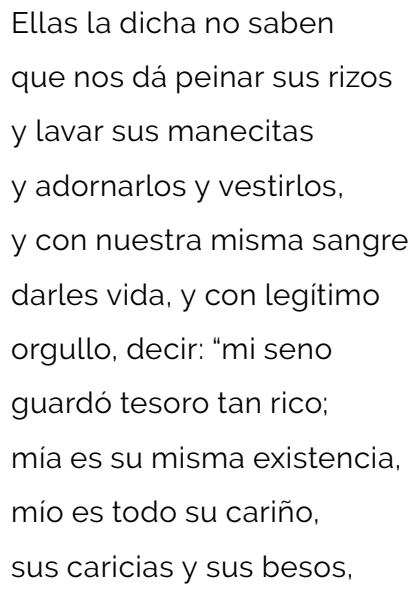


y su llanto, todo es mío!"

iAy, infelices mujeres

las que no tiene un hijo!

Al pasar de obligación a privilegio, la maternidad adquiere un carácter extraordinario. El amor maternal se revela fundamental y omnipotente:
La mujer que abandonada
va por la senda del vicio,
se tornara noble y pura
si acariciara algún hijo.

En la tercera parte de poema ocurren dos cosas, por un lado, la configuración discursiva de la mujer logra su vitalidad lírica y simbólica apropiándose de los atributos celestiales, sagrados e incuestionables de la virgen María:

iOh santo amor maternal,

amor sublime y sencillo!

eres tan grande y tan puro

que el mismo Dios tener quiso

una madre, que es tesoro,

emanación de Dios mismo. ${ }^{18}$

Y, al situar a la mujer en el horizonte del privilegio divino, también la coloca en una posición de autoridad moral por encima de los hombres al quedar configurada como la única capaz de sacrificarlo todo por un hijo:

iGracias, por bien tan supremo!
gracias mil y mil Dios mio,
por la dicha que me has dado
al darme este hermoso niño.
Que pierda salud y bienes
y cuanto tenga querido;
que pierda cuanto poseo;
pero déjame á mis hijos.

Si bien es cierto que en la poesía de Esther Tapia se advierte, de manea general, la representación de una mujer que reproduce la configuración femenina patriarcal, también manifiesta la importancia que el ejercicio de su capacidad creativa y su visión de mundo significó para la vida cultural y política del pais, y su protagonismo indiscutible en la construcción de la patria.

Josefina Hernández (2013) deja ver que el prototipo o deber ser de la mujer, transmitido a través de la educación, es una sucesión de tres siglos de dominación donde se conjuntan valores prehispánicos e hispánicos victorianos con una fuerte influencia de fundamentos biológicos e ideas religiosas, sobre todo de la religión católica, los cuales regulan la vida y comportamientos públicos y privados de las mujeres, desde una lógica patriarcal. Estos prototipos están ligados a la idea de la mujer como madre, esposa, ama de casa, etcétera, y se encuentran presentes en la escritura, sobre todo en círculos literarios y secciones femeninas en los periódicos.

En la poesía de Esther Tapia se observa cómo en la aceptación y reproducción de los roles tradicionales asignados al sujeto femenino, se encuentra también la configuración de una mujer consciente de su papel histórico, que a través de su aparente fragilidad, dependencia, vulnerabilidad y sumisión, refracta la importancia social de su labor como madre y esposa; es decir, por sus versos transita la voz de una mujer en pleno ejercicio y conocimiento de su Yo interno y su posición y lugar en el Mundo.

El estereotipo femenino de finales del siglo XIX consistía en la imagen de las mujeres ligadas únicamente al ámbito privado del hogar, dedicadas completamente al cuidado y atención de los hijos y del marido, preocupadas por su imagen con la intención de agradar y captar la atención de los demás. De acuerdo con algunas autoras como Josefina Quesada (2014) los estereotipos son un conjunto de ideas colectivas que arraigadas en la sociedad intentan explicar cómo es que se supone deben ser en la realidad, esas ideas son aceptadas y validadas culturalmente, por lo que cambian en cada grupo social. Los estereotipos contribuyen a la creación de imágenes mentales simplificadas sobre cosas, grupos y personas, establecen, por

18 Las negritas nos corresponden. 
decirlo de algún modo, la manera en que deben ser, cómo se deben ver y la forma en la que deben comportarse; fijan modelos que se pretende sean imitados por la sociedad a la que se dirigen. Los estereotipos de género entonces, son ideas socialmente establecidas sobre las expectativas de los comportamientos de hombres y mujeres.

Los estereotipos son aprendidos y transmitidos en los diferentes círculos sociales en los que se desarrollan los individuos, principalmente en la familia y la escuela, por otro lado, los medios de comunicación funcionan como transmisores de estos estereotipos de género, a través de sus publicaciones y de los diferentes lenguajes que éstos emplean; la prensa reproduce estereotipos presentes en la sociedad (GALLEGO, 2002).

Andrea Urrego apunta que "a través de algunos discursos presentes en la prensa se han construido representaciones y se ha promovido en los lectores de ambos géneros imaginarios acerca del papel que las mujeres debían cumplir en la sociedad" (2017, p.6). Urrego menciona que entre estas representaciones destacaban la de hijas, madres y esposas; también señala que este 'deber ser' estaba condicionado por relaciones asimétricas entre hombres y mujeres, las cuales dejaban a las mujeres sin voz propia dentro de la sociedad (URREGO, 2017, p. 54). En este sentido, para algunas autoras, las representaciones que hace la presa sobre las mujeres parten desde una perspectiva androcéntrica, por lo que la imagen de las mujeres es inferior o queda en segundo plano, o simplemente aparece en función de su relación con el hombre.

No obstante la obstinación patriarcal, Esther Tapia y las demás mujeres escritoras "Exaltadas como madres en el secreto del hogar [hicieron] derroche de voluntad restauradora" (MICHAUD, p. 155), y en su obra configuran un rostro y un espíritu femenino para una Patria que se vistió de mujer. La Patria poéticamente convertida en una madre simbólica se transfiguró en una mujer imaginaria de poderes inauditos. Depositaria de la crianza, la educación y la formación moral y espiritual de los hijos, se convirtió en la representación de la mujer mexicana.

Como mujer escritora, Esther Tapia fue valorada más por su condición de "ángel" de su hogar y por ocuparse de las actividades "propias de su sexo"; como muchas escritoras casi ausentes en un canon preponderantemente masculino ${ }^{19}$, sus versos participaron de una batalla artística e intelectual por la consolidación nacional ofreciendo la imagen de la nueva nación en su rostro y representación más importante: la patria mexicana.

De acuerdo con Adriana Sáenz, la Modernidad como forma ideológica ayudó en la configuración del pensamiento del hombre liberal e ilustrado, dándole forma a la educación del ciudadano y a la concepción de lo que Sáenz llama racionalidad patriarcal; con esto se determinó la división de espacios, la educación laica y la configuración del hombre como ciudadano y la mujer como ser para el espacio privado (Sáenz, 2011: 15). Estos aspectos han sido recreados, difundidos y reforzados a través de instituciones como la familia o las distintas producciones culturales como la música, la literatura o los periódicos, a lo largo del tiempo con sus debidas variaciones en cada época y lugar.

Edgardo Íñiguez (2011) dice que a la mujer se le ha definido como un ser incompleto, como el reflejo negativo del hombre y que por esta razón las mujeres son incapaces de definirse a sí mismas, pues los principios que rigen su comportamiento han sido impuestos por un modelo patriarcal que posteriormente ellas mismas reproducen, lo que implica un deber ser ligado a la idea de mujerhogar-maternidad-matrimonio y otras "virtudes" como la honestidad y la sensibilidad. Íñiguez define el deber ser femenino como "una serie de funciones sociales a desarrollar de acuerdo con ideologias fundadas sobre aspectos biológicos que logran asentarse en el imaginario" (IINNIGUEZ,

\footnotetext{
19 Con la apertura en 1869 de la Escuela Secundaria para Niñas y la aparición en 1873 de Las Hijas del Anáhuac, primera revista escrita por mujeres en México, comenzó el fortalecimiento de una actividad extramuros que la mujer mexicana habria de apropiarse muy bien en los años venideros; la actividad literaria emprendida por algunas mujeres, posibilitó no sólo la aparición de la mujer escritora, también su oportunidad de transgredir el espacio privado para introducirse al ámbito público con todo lo que ello representa en términos de libertad y autorreflexión. No obstante la calidad y cantidad de textos escritos por mujeres, que con Esther Hernández Palacios y Lilia Granillo podemos llamar "la edad de oro de las poetisas mexicanas" (2010, p. 121), el peso del pensamiento patriarcal no permitió su merecida entrada al canon.
} 
2011, p. 86). Se presenta entonces una diferencia entre lo que se es y lo que se pretende que debe ser, aunque este deber ser intente regir lo público y lo privado del ser y hacer femenino.

\section{Comentarios finales}

La obra poética de Esther Tapia es pieza clave para la comprensión de dos fenómenos culturales fundamentales en el proceso de construcción del proyecto nacional de los liberales mexicanos; desde la perspectiva del uso político de la literatura, contribuye a la configuración de un/otro sentido de Patria, pues sus poemas proponen imágenes femeninas que dotan de rostro y sentimiento a la idea de nación que procuraba asentarse por aquellos años; desde la representación puramente literaria, su poesía está llena de retratos del deber ser de la mujer mexicana. En la comunión de ambos aspectos la poesía de Esther Tapia es, al mismo tiempo, un ejercicio de aceptación de los roles tradicionalmente impuestos a la mujer y un acto subversivo en contra de éstos, si consideramos que la incursión de las mujeres en el ámbito de la creación literaria rebasa los límites del espacio cerrado e íntimo del hogar y se apropia de los escenarios públicos reservados al varón.

La noción de Patria se apoyaba en la imagen tradicional de la mujer como depositaria del cuidado del hogar y la educación de los futuros ciudadanos del México independiente. Lo anterior en un contexto en el que las mujeres del siglo XIX fueron confinadas a la figura del "ángel del hogar", encargada del cuidado de los hijos, el marido, los padres, los hermanos e incluso de otras mujeres. Los mecanismos poéticos empleados por Esther Tapia refractan al sujeto femenino en los textos de esta autora que sirvió como ejemplo de mujerescritora para otras mujeres.

La existencia textual de las mujeres, la configuración artística de su deber-ser, pareció fundirse y confundirse en una imagen que transitabay contenía tanto la vida práctica, real, como su presencia objetivada literariamente, encarnando un ideal construido por los hombres que debía sostenerse inmaculado y dócil por el bien de la nación.

\section{Referencias}

DÍAZ Alejo, Ana Elena; PRADO Velázquez, Ernesto. Estudio preliminar. In: VIGIL, José María. Poetisas mexicanas. Siglos XVI, XVII, XVIII y XIX. Antologia formada por encargo de la Junta de Señoras correspondiente de la Exposición de Chicago. Edición facsimilar, México: UNAM, 1977. 1893. https://doi. org/10.31819/9783954875849-010

GALLEGO, Juana. La prensa por dentro: producción informativa y transmisión de estereotipos de género. México: Los Libros de la Frontera, 2002.

GREENFELD, Liah. Nacionalismoe i modernitat. Catarroja-Valencia: Afers-Universitat de València, 1999.

GRANILLO Vázquez, Lilia. Escribir como mujeres entre hombres: historia de la poesia femenina mexicana del siglo XIX. México: Universidad Autónoma Metropolitana-Azcapotzalco, 2010. https://doi. org/10.19130/iifl.litmex.30.1.2019.1166

HERNÁNDEZ, Josefina. "La educación femenina del siglo XIX: su preservación y reforzamiento en discursos del siglo XXI". In: FLORES, Sandra; HERNÁNDEZ, Elvira; HERNÁNDEZ, Josefina. 2010-1910-1810 Revoluciones Femeninas. México: UAEH, 2013. p. 187-193. https://doi.org/10.2307/i.ctv47w8dd.6

HERNÁNDEZ Palacios, Esther y GRAILLO Vázquez, Lilia. De reinas del hogar y de la patria a escritoras profesionales: la edad de oro de las poetisas mexicanas. In: CLARK de Lara, Belem y SPECKMAN Guerra, Elisa (ed.). La República de las Letras. Asomos a la cultura escrita del México decimonónico. México: UNAM, 2005. v. 1. p. 121-152. https://doi. org/10.2307/j.ctv47wf39.12

INFANTE Vargas, Lucrecia. De la escritura personal a la redacción de revistas femeninas. Mujeres y cultura escrita en México durante el siglo XIX. Relaciones: estudios de historia y sociedad, Zamora, MX, año XXIX, n. 113, p. 69-105, 2008. https://doi. org/10.24901/rehs.v37i148.223

IÑ̃IGUEZ, Edgardo. "Género y melancolia: acercamiento a los roles arquetípicos de la mujer en El temperamento melancólico, de Jorge Volpi". In: SÁENZ, Adriana (coord.). Los prototipos de hombres y mujeres a través de los textos latinoamericanos del Siglo XX. México: UMICH, 2011. p. 79-96. https://doi. org/10.1163/9789042029002_008

MICHAUD, Stéphane. Idolatrias: representaciones artísticas y literarias. In: DUBY, Georges; PERROT, Michelle (dir.). Historia de las mujeres. México: Taurus, 2005. t. IV: El Siglo XIX, p. 153-180.

PADILLA, Antonio. Para una historiografía de la vida escolar en el siglo XIX. In: GALVÁN Lafraga, Luz Elena (coord.). Diccionario de la historia de la educación en México. $2^{\mathrm{a}}$. ed. México: UNAM, 2002. Disponivel em: http://biblioweb.dgsca.unam.mx/diccionario/ htm/articulos/sec_19.htm Acesso em: 29 out. 2019. https://doi.org/10.2307/j.ctv26dgmw.10 
PÉREZ-RAYÓN, Nora. "La prensa liberal en la segunda mitad del siglo XIX". In: CLARK Lara, Belem; SPECKMAN Guerra, Elisa (ed.). La República de las Letras. Asomos a la cultura escrita del México decimonónico. México: UNAM, 2005. v. II, p. 145-158. https://doi. org/10.3989/aeamer.2006.v63.i1.3

QUESADA, Josefa. "Estereotipos de género y usos de la lengua. Un estudio descriptivo en las aulas y propuestas de intervención didáctica". 2014. 608 f. (Tesis de doctorado) - Facultad de Derecho, Universidad de Murcia, Murcia, 2014. https://doi.org/10.6018/riite/2018/30001

RIVA PALACIO, Vicente. El Parnaso Mexicano. México Imprenta de Ignacio Escalante, 1871.

SÁENZ, Adriana. Una mirada a la racionalidad patriarcal en México en los años cincuenta y sesenta del siglo XX. Estudio de la moral en Los años falsos de Josefina Vicens. Madrid: Plaza y Valdés, 2011. https:// doi.org/10.29351/rmhe.v7i13.176

SOSA, Francisco. "Esther Tapia de Castellanos". In: RIVA Palacio, Vicente (dir.). El Parnaso Mexicano. México: Librería La llustración, 1885. p. 5-13.

TAPIA de Castellanos, Esther. Obras Poéticas. México: Talleres de Luis G. González, 1905. Tomo I, Guadalajara.

TAPIA de Castellanos, Esther "Sobre el sepulcro del desgraciado jóven D. Juan D. Cobarruvias, despues de haber leido un tomo de sus poesias". La Bandera Roja, México, n. 159. t. I, p. 4, 23 de nov. 1860

TAPIA de Castellanos, Esther. "La Patria". La Lira Michoacana, Zamora, México, p. 640-641, 1894

TAPIA de Castellanos, Esther.."A mi hijo". La Mujer Mexicana, México, p. 65-66, 1901

TAPIA de Castellanos, Esther. "Amor de madre". La Mujer Mexicana, México, p. 92-93. 1901.

TAYLOR, Charles. Fuentes del yo. La construcción de la identidad moderna. Barcelona: Paidós, 1996.

TORRES, Mariano de Jesús. "La Misión de la Mujer". La Mujer Mexicana, México, p. 35-36.1901.

TORRES, Mariano de Jesús. "Introducción". La Mujer Mexicana, México, p. 3-4, 1901.

URREGO, Andrea. "Los ángeles de la paz. Representación de las mujeres en la prensa antioqueña en la década de 1920". 2017. (Tesis de licenciatura) Universidad de Antioquia, Medellín, Colombia, 2017. https://doi.org/10.18273/revsal.v50n3-2018006

VELÁSQUEZ, Federico. "El Prisma". En El Prisma, 1. época, n.. 1, p. 1-3, 10 jun. 1881.

VIGIL, José Ma. Poetisas mexicanas. Siglos XVI, XVII XVIII y XIX. Antología formada por encargo de la Junta de Señoras correspondiente de la Exposición de Chicago. Edición facsimilar, estudio introductorio Ana Elena Díaz Alejo y Ernesto Prado Velázquez. México: UNAM, 1977. 1893.

\section{Dirección}

Gabriela Sánchez Medina

Avenida Francisco J. Mujica S/N Ciudad Universitaria, C.P: 58030

Ariadna Alvarado López

Avenida Francisco J. Mujica S/N Ciudad Universitaria, C.P. 58030

\section{Gabriela Sánchez Medina}

Doctora en Filosofia, profesora e investigadora de tiempo completo en la Facultad de Letras de la Universidad Michoacana de San Nicolás de Hidalgo, en donde desarrolla las lineas de investigación de: mujeres en la prensa de los siglos XIX y XX y estudios de género, desde la perspectiva discursiva. A partir de 2020 miembro del Sistema Nacional de Investigadores de su país. Actualmente es Directora General de Bibliotecas de la Universidad Michoacana.

\section{Ariadna Alvarado López}

Doctora en Humanidades y Artes, profesora e investigadora de tiempo completo en la Facultad de Letras de la Universidad Michoacana de San Nicolás de Hidalgo. Trabaja las líneas de investigación: literatura canónica y no canónica, poesía del siglo XIX, con énfasis en la configuración discursiva de los sujetos sociales. Ha publicado un buen número de artículos y capitulos de libros, entre los que destaca "¿Quién es más pudorosa que mística azucena? Las imágenes de la virgen en la poesia de Esther Tapia de Castellanos" (2017) 